\title{
Leaders
}

\section{Skiing helmets}

As the winter sports season is now upon us, those of us who work in sports injury clinics will be expecting the usual influx of skiing and snowboarding injuries to start arriving with the winter snow. Despite improvements in boot, binding, and ski design over the years, skiers are still more likely to injure their knees $^{1}$ than any other area. Snowboarders are just as likely to get injured as skiers. ${ }^{2}$ Both have injury rates of around two to three per 1000 skier or snowboarder days, ${ }^{3}$ but snowboarders are more likely to injure the upper limb with a high proportion of these injuries being fractures. ${ }^{45}$

In one study of severe snowboarding injuries, mild head injury was reported in $54 \%$ of these. ${ }^{6}$ But rather more worryingly, a report on children and adolescents injured in a wide range of winter sports (skiing, sledging, ice hockey, and ice skating) indicated that brain injury was the most commonly occurring injury, at $46 \%$ of all injuries.

A five year study of skiing injuries in children and adolescents $^{7}$ published in 1996 showed that head injuries were very common, with skull fractures in 27 out of 38 cases. Some $58 \%$ were caused by collisions with stationary objects. Long term sequelae were associated with $26 \%$, and helmet use was negligible. The obvious conclusion was that helmet use should be encouraged in young recreational skiers.

Recently there have been two well publicised deaths from head injury in skiing: a member of the Kennedy family and Sonny Bono, the singer, were both killed by collisions with trees. There was a lot of discussion at the time about the wearing of helmets for recreational skiers, and, as we are in the business of injury prevention as well as treatment, we should consider whether or not we should be recommending helmet use to our patients.

The facts speak for themselves as far as children are concerned. However, it is not as simple when dealing with adults. If every recreational skier wore a helmet, there is no doubt that some head injuries would be prevented, but we must bear in mind that fatal head injuries are rare and even if we all wore helmets when skiing, fatalities would still occur. A 20 year old female member of the British Alpine Ski team was killed a few years ago when she fell in training for a downhill race. She was wearing a helmet. The wearing of helmets is compulsory for competitors in downhill and super giant slalom events. These racers are reaching speeds in excess of $60 \mathrm{mph}$. They would not sit on a motorbike at that speed without a helmet and so need little persuasion to wear helmets. Generally speaking, recreational skiers do not reach the speeds of those competing in World Cup races, but neither do they have the skill of World Cup racers, and injury is more likely to occur with less experienced skiers.
If we assume that we would all be safer in helmets and recommend wearing them, then we are likely to have the same problem as has occurred in cycling: simply refusal to wear them. One of the great joys of skiing and snowboarding is the feeling of freedom from gliding at speed down wide open and occasionally empty slopes. Anything that infringes that freedom would be resisted. We do not have as much evidence for the general recommendation of protective headgear in skiing as we do for cycling (and there are those who still dispute the necessity for cycle helmets). Some of those who don helmets may begin to believe that they are World Cup racers, but there is an enormous ability gap between good recreational skiers and professional racers. Once you put on a helmet you may feel rather too protected and push yourself beyond your limits. That is when accidents happen. If not wearing a helmet makes you a slower and more careful skier, then perhaps this is preferable. I would, however, recommend that all children should have head protection.

Some $60 \%$ of injured skiers said that their injury could have been avoided. ${ }^{8}$ Most thought that behaviour modification was the most likely prevention strategy, which is best provided by ski instructors and ski patrollers. We cannot prevent all head injuries, but we must look at the balance of risk. Head injury occurs in many sports and, apart from in boxing, is accidental. Repeated mild injury can result in cumulative brain damage. ${ }^{9}{ }^{10}$ In skiing this does not appear to be a major problem. However, if you have ever lived with a skiing addict, you may wish to dispute this.

ADRIENNE REES-JONES

Eastbourne District General Hospital

1 Davidson TM, Laliotis AT. Alpine skiing injures. A nine-year study. West $\mathcal{F}$ Med 1996;164:310-14.

2 Fischler L, Rothlisberger M. Comparison between ski and snowboarding accidents: current overview from the ski area Arosa (Switzerland) (1988/89 to 1994/95). Schweiz Rundsch Med Prax 1996;85:777-82.

3 Langran M, Jachacy GB, MacNeill A. Ski injuries in Scotland. A review of the statistics from Cairngorm ski area winter 1993/4. Scot Med f 1996;41: 169-72.

4 Sutherland AG, Holmes JD, Myers S. Differing injury patterns in snowboarding and alpine skiing. Injury 1996;27:423-5.

5 Davidson TM, Laliotis AT. Snowboarding injuries, a 4 year study with comparison with alpine ski injuries. West f Med 1996;164:231-7.

parison with alpine ski injuries. West $\mathcal{F}$ Med 1996;164:231-7.
6 Prall JA, Winston KR, Brennan R. Severe snowboarding injuries. Injury 1995;26:539-42.

7 Shorter NA, Jensen PE, Harmon BJ, et al. Skiing injuries in children and adolescents. F Trauma 1996;40:957-1001.

8 Metz MM, Jackson RI, Williams JM, et al. An analysis of skiing injuries in West Virginia. WV Med F 1957;93:68-71.

9 McLatchie G, Jennett B. Head injury. Sports Exercise and Injury 1995;3:11823.

10 MMWR Morb Mortal Wkly Rep 1996;45:209-11. 


\section{Clinical coding in sports medicine-it's good to talk}

As the millennium approaches, we are seeing ever increasing emphases on quality, audit, effectiveness, and benchmarking of clinical practice. Clinical governance is upon us, and sports medicine practitioners need to grasp the nettle, whatever their discipline. But it is not just about things imposed from outside, it is also about furthering our understanding of our own clinical practice: what works and what doesn't, why the patient has ended up having to see us in the first place, and how he or she could have been prevented from reaching that point. On top of that we all know intuitively that sports medicine services within the NHS are extremely variable, difficult to access, and often fail to meet the needs of both elite and recreational athletes. Changes that may have profound effects on sports medicine services are afoot. Most sports injuries that present to health services are looked after in primary care. ${ }^{1}$ The advent of primary care groups will potentially provide a golden opportunity to improve the services currently available. We can only persuade commissioning bodies to invest in service development if we can measure the unmet need, demonstrate the effectiveness of sports medicine interventions, and show that it will not break the bank.

What is necessary therefore is a standardised language to capture our clinical practice in a way that is consistent and can be understood and used by both clinicians and computers $^{2}$ - that is, we need to be able to code our information, enter it, and retrieve it in a form that is useful and meaningful. There are numerous coding systems and practices in existence, and a wealth of literature discussing both their value and their pitfalls. Opinion is united that the accurate and efficient retrieval of medical data is essential to the functioning of any medical system, ${ }^{3}$ and that coding and classification systems are expected to become increasingly important in the effort to improve quality and effectiveness. ${ }^{4}$ As information technology increases in prevalence and sophistication, more detailed data can be coded and processed than was possible previously. ${ }^{3}$ In the United Kingdom, the most commonly used clinical coding systems are the International Classification of Diseases (ICD) 9th and, more recently, 10th revisions (used chiefly by hospitals), the Read codes (used mostly in primary care), and the ONS procedure classifications. It is not the place of this article to debate in depth the merits or otherwise of these three, other than to say that there is opinion that none currently fully support all of the functions I have highlighted, and that people have been compelled to try to develop their own specific coding systems ${ }^{5}$; sports medicine is no exception. ${ }^{6}{ }^{7}$ However, disparate attempts to create these systems have created data incompatibility, ${ }^{8}$ and there are a number of sports medicine initiatives in development that illustrate this well.

The National Sports Medicine Institute is currently piloting a national injury register in partnership with sports medicine centres at the Universities of Nottingham, Liverpool, and Edinburgh and the British Olympic Medical Centre at Northwick Park. It is hoped that the database will eventually be used at all United Kingdom sports medicine centres. Areas that will need to be addressed before the next phase include expanded information technology provision to enable coding to take place in the consulting room, a review of the diagnostic codes used, and the development of sports medicine specific outcome measures. A database created from the network of sports injuries clinics in Scotland, initially supported by the Scottish Sports Council and now by the Scottish Institute of Sports Medicine and Sports Science, has also provided important epi- demiological data on sports injury clinic attendance, ${ }^{9}$ but, although both initiatives are to be applauded, differences in data recording and diagnostic coding prevent direct comparison between the two groups.

This lack of a consistent approach to coding is also seen within the field of research. ${ }^{10}$ The Football Association audit of injuries is providing much useful information about the injuries seen in professional football but will not be easily integrated into similar work on different sporting populations. ${ }^{11}$

There are a number of key elements to the development of a successful sports medicine coding system; defining precisely what you want the system to do and who it will be used by is the crucial first step. Recognising that sports injuries present to health services in numerous different places and that there will be consequent variation in diagnostic practice means that a single coding system is unlikely to serve everyone's needs. However, it is important that wherever possible there is consistency in coding wherever the athlete presents for sports medicine care. The ability to expand, collapse, and cross reference clinical codes should enable consistent user friendly systems to emerge, if this is highlighted at the design stage. The essential features of the most basic sports medicine coding system should include the ability to accurately attribute injury to a given sport or recreational pursuit, the recording of possible aetiological factors, and a record of diagnosis, investigations, treatment, and importantly outcome.

So what is the way forward? We must recognise that a piecemeal approach to the development of sports medicine specific coding systems is unlikely to provide an appropriate solution. Although the United Kingdom Sports Institute is likely to provide an embedded information technology network for its hub and regional centres that will enable important data to be collected on elite and emerging talent, coding systems will still need to be developed, and funded, for use in primary and secondary care, and the, as yet partially defined, research agenda also still needs to be developed. Identifying the agency that is best placed to lead such work is an important next step.

Although sports medicine coding is in its infancy in the United Kingdom, there has been a great deal of investment in the general field of coding that we can draw on. Coding in primary care with the Read codes, one of the few systems to cover diagnosis, investigation, and treatment, as well as allowing hierarchical levels of detail and mapping into more widely used systems, is well established and can teach us important lessons. The Clinical Terms Project to develop the Read codes involved collaboration with over 40 medical and paramedical colleges. ${ }^{8}$ Unfortunately, this project has not to date specifically included sports medicine and therefore work would need to be done if Read codes were to form the basis of our coding system.

In conclusion, we need to address this, and address it soon. There is plenty of expertise and experience for us to draw on, so we have no excuse. Sports medicine is a specialty in evolution, and it cannot develop its full potential while it lacks the tools with which we can talk to each other.

SIMON KEMP

Sports Physician, Parkside Hospital, Wimbledon, London SW19 5NX

\footnotetext{
1 Nicholl JP, Coleman P, Williams BT. Injuries in sport and exercise. London: Sports Council, 1993.

2 Tabaqchali MA, Venables CW. The clinical terms project: its potential for computerised surgical audit. Ann R Coll Surg Engl 1995;77(suppl 3):124-9.
} 
3 Vardy DA, Gill RP, Israeli A. Coding medical information: classification verus nomenclature and implications to the Israeli medical system. $7 \mathrm{Med}$ Syst sus nomenclature

4 Engum B, Solheim BG. Medical coding and classification systems. Tidsskr Nor Laegeforen 1994;114:694-6.

5 Cimino JJ. Review paper: coding systems in health care. Methods Inf Med 1996;35:273-84.

6 Orchard J. Orchard sports injury classification system (OSICS). Sport Health 1993;11:39-41.

\section{Sports medicine at work}

Occupational medicine and musculoskeletal (orthopaedic) medicine are natural bedfellows with the discipline of sport and exercise medicine. The main thrust of occupational medicine is prevention of health problems caused by the job and maintenance of optimum health for the job, together with rehabilitation back to the job after illness or injury. Multidisciplinary work is essential, very similar to the work of a doctor attached to a sports team. Knowledge of muscle and exercise physiology, combined with goal setting methods (taught by sports psychologists) allow the clinician to set realistic and achievable programmes of rehabilitation back to work. These are the same principles whatever the level of human performance; patients with chronic fatigue syndrome or fibromyalgia and heart attack victims stand to gain just as much benefit as the athlete recovering from injury. Goal setting and careful rehabilitation is essential for a worker returning after a mental health problem. In professional sports teams, a player would never be returned directly to play a full match in the first team after injury without first being tested in the reserves for a period to build up confidence and match fitness. The same should apply to any organisation's most valuable asset: its human work force.

Sports medicine teaches identification of the intrinsic and extrinsic causes of injury so that the risk of recurrence can be reduced. Work related musculoskeletal problems must be approached in the same way, particularly upper limb disorders; failure to recognise contributing ergonomic factors frustrates treatment. Clinicians trained in sports medicine will have little difficulty in recognising and managing work related upper limb problems that have a clearly identified histopathological diagnosis, now sometimes called type 1 disorders ${ }^{1}$ - for example, shoulder impingement, peritendinitis crepitans, and enthesopathies. Increasing numbers of jobs involve prolonged and frequently awkward static postures, particularly in the service sector and light manufacturing. The muscles involved in maintenance of these postures are not designed through evolution for such activity. Prolonged isometric contraction is one factor commonly identified as contributing to "diffuse" work related upper limb pain, the type 2 disorder according to Hutson. ${ }^{1}$ Musicians are prone to the same complaints. ${ }^{2}$ There are not enough opportunities for exercise in the daily routines of most such workers, and this is compounded by
7 Harvey D. Sports injury surveillance. Sport Health 1997;15:43-4.

8 Information Management Group. NHS centre for coding and classification general information. London: NHS Management Executive, 1992. general information. London: NHS Management Executive, 1992.
Neilsen A, Knill-Jones R. Usage of sports medicine clinics in Scotland. Glasgow: Neilsen A, Knill-Jones R. Usage of
Scottish Sports Council, 1996.

10 Lower T. Injury data collection in the rugby codes. Aust $\mathcal{F}$ Sci Med Sport 1995;27:38-42.

11 Football Association Medical Education Centre. Audit of injuries in professional football: individual club review. London: Football Association, 1998. motorised travel to the workplace and sedentary lifestyles. These factors may also be contributing to the exponential rise in back pain disability. ${ }^{3}$ Knowledge of appropriate exercise prescription, both for general health and the specific problem, is invaluable to the doctor in managing these disorders.

The sports medicine curriculum does not provide the physician with all the skills to manage musculoskeletal disorders: study of and practice from the schools of Cyriax, ${ }^{4}$ Travell and Simons, ${ }^{5}$ and Gunn, ${ }^{6}$ and osteopathic medicine broadens the range of therapeutic options for musculoskeletal disorders.

Workplace psychosocial factors frequently place a spin on the presentation and outcome of musculoskeletal problems quite different from the sports team; these are probably best learnt in the workplace. Sport and exercise medicine is at a critical stage of development as the discipline tries to establish a career structure and specialist recognition. To gain credibility in the medical hierarchy, doctors who are specialising must be able to show that they can apply their skills in a wide range of clinical activities for the benefit of all human performance in addition to the sporting arena. Occupational medicine can learn from sports medicine and vice versa; when the latter has a training structure established, a period of time spent by the trainee in a workplace, military training establishment, orchestra, or ballet company would be extremely useful for both parties. After all, what is work? Special adaptations are required of the human body whether it is trained to run a marathon, throw javelins, play a violin, use a hand tool all day, or sit in front of a display screen.

GRAHAME J BROWN

Orthopaedic and Sports Physician, Royal Orthopaedic Hospital, Birmingham, Occupational Health Physician, University of Birmingham, Honorary Clinical Lecturer, Institute of Occupational Health and School of Sport and Exercise Science, University of Birmingham

\footnotetext{
1 Hutson MA. Work-related upper limb disorders: recognition and management.

Oxford: Butterworth-Heinemann, 1997.
Maran AGD. Performing arts medicine. Br f Sports Med 1998;32:5.

2 Maran AGD. Performing arts medicine. Br $\mathcal{F}$ Sports Med 1998;32:5.

3 Clinical Standard Advisory Group. Back pain. London: HMSO, 1994 . London: WB Saunders Company, 1995.

5 Travel JG, Simons DG. Myofascial pain and dysfunction. The trigger point manual. Baltimore: Williams and Wilkins, 1983.

6 Chan Gunn C. The Gunn approach to the treatment of chronic pain. Edinburgh: Churchill Livingstone, 1997.
} 